\title{
Heterologous Expression of Dehydroascorbate Reductase from Rice and Its Application to Determination of Dehydroascorbate Concentrations
}

\author{
Katsumi AmAKo ${ }^{1,2}$, Takashi Ushimaru ${ }^{3}$, Ayami IshiKAWA ${ }^{1}$, Yasuka OGISHI ${ }^{1}$, \\ Ritsuko KISHIMOTO $^{1}$ and Kiyoshi GoDA ${ }^{1,2}$ \\ ${ }^{1}$ Faculty of Nutrition, and ${ }^{2}$ High Technology Research Center, Kobe Gakuin University, \\ 518 Arise, Ikawadani-cho, Nishi-ku, Kobe 651-2180, Japan \\ ${ }^{3}$ Department of Biology and Geosciences, Faculty of Science, Shizuoka University, \\ 836 Ohya, Shizuoka 422-8529, Japan
}

(Received October 6, 2005)

\begin{abstract}
Summary We constructed an expression vector for rice dehydroascorbate reductase (DHAR) (EC 1.8.5.4) with a polyhistidine tag at the amino terminus and introduced the vector into several strains of Escherichia coli. On conventional induction treatment with isopropylthiol- $\beta$-D-galactoside, E. coli harboring rice DHAR cDNA produced doublet polypeptides of about $27 \mathrm{kDa}$. Induction duration or growth temperature did not affect the ratio of these polypeptides. Only the larger polypeptide, corresponding to full-length recombinant DHAR, was produced in E. coli supplemented with tRNAs for several minor codons. Most of the enzymatic characteristics of the recombinant DHAR were similar to those of the native one, although the recombinant protein showed increased heat susceptibility. Using recombinant DHAR, we developed a method for simple and precise determination of dehydroascorbate concentrations in tissue extracts by spectrophotometry, and we successfully applied the method to several fruit juices and vegetables.
\end{abstract}

Key Words ascorbic acid, dehydroascorbate, dehydroascorbate reductase, quantification

Aerobic organisms are able to produce energy highly efficiently using dioxygen, but they inevitably suffer from attacks by reactive oxygen species (ROS). There are multi-component systems for protection against ROS in living organisms, and even in anaerobic organisms (1). Ascorbate (AsA) is one of the most ubiquitous antioxidants acquired by living organisms. In humans, AsA is indispensable for a broad range of physiological processes as well as the removal of ROS, biosynthesis of collagen and cathecholamine, and promotion of iron uptake accompanying the reduction of ferrous ion. Humans lack the gene for L-gulono-1,4-lactone oxidase, which catalyzes the final step of AsA biosynthesis in mammals (2), so AsA must be obtained exogenously, usually from fresh vegetables and fruits.

In higher plants, AsA can be detected at quite high concentrations (1-300 mM) (3) and plays a central role in the scavenging of ROS (4). Wheeler et al. (5) have proved that AsA is synthesized mainly from D-glucose via GDP-mannose, L-galactose, and L-galactono-1,4lactone. Some novel shunts for AsA biosynthesis have also been reported recently (6). Higher plants use AsA as an electron donor for AsA peroxidase for scavenging of ROS (7), and this is quite distinct from the case in mammals, which use GSH for selenocysteine-containing glutathione peroxidase. A univalently oxidized form of AsA, monodehydroascorbate (MDA), is produced by the catalytic reaction of AsA peroxidase, and MDA is

\footnotetext{
E-mail: amakok@nutr.kobegakuin.ac.jp
}

reduced back to AsA through three routes (4): reduction by ferredoxin localized in chloroplasts $(8)$; reduction by $\mathrm{NAD}(\mathrm{P}) \mathrm{H}$-dependent MDA reductase $(9,10)$; and reduction by dehydroascorbate reductase (DHAR) (EC 1.8.5.1) following spontaneous disproportionation of MDA to AsA and dehydroascorbate (DHA).

DHAR in higher plants has been purified and characterized from spinach leaves (11), spinach chloroplasts (12), rice (13), and wheat (14). Assuming that AsA content is defined by the balance between synthesis and decomposition, recycling of AsA can have a major influence on AsA content and is especially important under conditions of stress $(15,16)$. In addition, DHA itself, or the redox balance of AsA and DHA, has also been recognized to possess physiological roles in plant cells, e.g., cell cycle progression (17) and cell elongation $(18,19)$. In mammalian cells, DHA acts as an inhibitor of $\mathrm{I} \kappa \mathrm{B} \alpha$ kinase $\beta$ and suppresses transcriptional activation by nuclear factor $(\mathrm{NF}) \kappa \mathrm{B}(20)$. Assuming that intracellular DHA levels are generally kept quite low, subtle changes in the redox balance would be a trigger for responses to environmental stress. To understand AsA-related physiological changes and stress responses, a simple and precise assay of DHA would be quite helpful. We report here the heterologous production of recombinant rice DHAR (rDHAR) in Escherichia coli, with a dramatic improvement in expression efficiency by supplementation of tRNAs for minor codons. We also developed a simple and precise protocol for determining DHA concentration, and applied it to several plant food materials. 


\section{MATERIALS AND METHODS}

Preparation of dehydroascorbate. Commercial DHA is quite impure (21), so DHA was prepared in a laboratory from AsA (Wako Pure Chemical Industries, Ltd., Osaka). AsA (100 mM) dissolved in distilled water was mixed with an equal volume of bromine water (about 3\% (w/v), Nacalai Tesque, Inc., Kyoto), and bubbled with nitrogen gas on ice for 5 min to remove the yellow color. Prepared DHA was used within $6 \mathrm{~h}$.

Expression and purification of recombinant DHAR.

The expression vector of rice DHAR (pQE-DHAR1) was prepared as described previously (22). The vector was transformed into E. coli strains M15 and SG13009 (Qiagen, Tokyo) and the BL21(DE3) Codon-Plus recombinant inbred line (RIL) (BL21-RIL) (Stratagene) harboring pREP4 (Qiagen) in the presence of $50 \mu \mathrm{g} / \mathrm{mL}$ ampicillin and $10 \mu \mathrm{g} / \mathrm{mL}$ kanamycin sulfate. We also added $30 \mu \mathrm{g} / \mathrm{mL}$ chloramphenicol to the BL21(DE3)RIL strain. Transformant cells in $40 \mathrm{~mL}$ Luria-Bertani medium were grown at $37^{\circ} \mathrm{C}$ until an $\mathrm{OD}_{600}$ of 0.6 was reached, and induction of DHAR production was started by the addition of isopropyl- $\beta$-D-thiogalactopyranoside (IPTG) to a final concentration of $1 \mathrm{mM}$. After incubation for another $3 \mathrm{~h}$, cells were collected by centrifugation at $3,000 \times g$ for $5 \mathrm{~min}$ at $4^{\circ} \mathrm{C}$, and suspended in $1 \mathrm{~mL}$ equilibration buffer composed of $50 \mathrm{mM}$ Tris$\mathrm{HCl}$ (pH 8.0), $20 \mathrm{mM} \beta$-mercaptoethanol ( $\beta \mathrm{ME}$ ), 15\% glycerol, and $40 \mathrm{~mm} \mathrm{NaCl}$. Immediately after addition of $1 \mathrm{~mm}$ phenylmethylsulfonylfluoride and $10 \mu \mathrm{g} / \mathrm{L}$ pepstatin A to the E. coli suspension, it was subjected to repeated sonications ( $5 \mathrm{~W}, 10 \mathrm{~s} \times 10$ times) with a Microson Cell Sonic Disruptor (Misonix, Farmingdale, $\mathrm{NY}$ ), then centrifuged at $21,600 \times g$ for $20 \mathrm{~min}$ at $4^{\circ} \mathrm{C}$. The supernatant was applied to a column (1.5 i.d. $\times$ $2.0 \mathrm{~cm}$ ) of $\mathrm{Ni}^{2+}$-chelated Ni-NTA Superflow (Qiagen) equilibrated with an equilibration buffer. After the column had been washed with $10 \mathrm{~mL}$ of $50 \mathrm{~mm}$ Tris-HCl (pH 8.0) containing $20 \mathrm{~mm} \beta \mathrm{ME}, 15 \%$ glycerol, $50 \mathrm{mM}$ $\mathrm{NaCl}, 0.5 \mathrm{~mm} \mathrm{MgCl}_{2}, 0.1 \mathrm{~mm}$ EDTA, and $20 \mathrm{~mm}$ imidazole, the DHAR-enriched fraction was eluted by increasing the concentration of imidazole to $200 \mathrm{mM}$. Active fractions were concentrated with Ultrafree-MC (Cut-off $M W=5 \mathrm{kDa}$, Millipore, Bedford, MA), dialyzed with equilibration buffer, and pooled at $-70^{\circ} \mathrm{C}$. Purified DHAR was stable for at least 3 mo.

Enzyme Assay. DHAR activity was determined by the method of Kato et al. (13), with slight modifications. The reaction was initiated by the addition of a reduced form of glutathione $(2 \mathrm{mM})$, to the assay mixture (total volume, $1 \mathrm{~mL}$ ), which contained $50 \mathrm{~mm}$ potassium phosphate ( $\mathrm{pH} 7.8$ ), 0.1 mM DHA, and the enzyme. The reaction was run at room temperature, and then absorbance was monitored at a wavelength of $265 \mathrm{~nm}$ (the extinction coefficient of ascorbate was taken as $14.0 \mathrm{mM}^{-1} \mathrm{~cm}^{-1}$ ) using a UV2010 spectrophotometer (Shimadzu, Kyoto).

Preparation of AsA and DHA extracts. Fruits juices and vegetables were purchased from a local market. Icecold orange and grapefruit juices were mixed with an equal volume of $10 \%(\mathrm{w} / \mathrm{v})$ metaphosphoric acid and kept on ice for $10 \mathrm{~min}$. Spinach and onion (about $5 \mathrm{~g}$ ) were chopped and ground with a mortar and pestle with $10 \%(\mathrm{w} / \mathrm{v})$ metaphosphoric acid in an equal volume and an aliquot of sea sand. These resultant extracts were centrifuged at $21,600 \times g$ for $10 \mathrm{~min}$ at $4^{\circ} \mathrm{C}$. The supernatants were stored on ice until use.

AsA and DHA determination. A volume of $0.2 \mathrm{M}$ potassium phosphate buffer $(\mathrm{pH} 7.4)$ containing $1 \mathrm{mM}$ EDTA and a two point fifth of each extract were mixed in to give a $\mathrm{pH}$ of about 6.0. This neutralized solution was immediately applied to the AsA and DHA determinations by the protocol which we called the ASO and DHAR method. To determine the AsA concentration, we applied this solution to a mixture of $0.1 \mathrm{M}$ potassium phosphate buffer ( $\mathrm{pH}$ 6.0) containing 1 mM EDTA and 0.1 unit of ascorbate oxidase (ASO) from cucumber (Type III, Toyobo, Osaka) in a $1 \mathrm{~mL}$ total volume. The AsA concentration was determined from the decrease in absorbance of ascorbate at a wavelength of $265 \mathrm{~nm}$ after completion of the enzyme reaction. To determine the DHA concentration, the neutralized solution was applied to a mixture of $0.1 \mathrm{M}$ potassium phosphate buffer ( $\mathrm{pH}$ 6.0) containing $1 \mathrm{mM}$ EDTA, $2 \mathrm{~mm}$ reduced glutathione, and 0.2 unit of rDHAR in $1 \mathrm{~mL}$ of total volume. From the increase in absorbance of ascorbate after completion of the enzyme reaction, the DHA concentration was determined. Both ASO and DHAR treatments were practically accomplished within $5 \mathrm{~min}$. Alternatively, the classical hydrazone formation method (23) was applied as the reference for AsA and DHA determination. Photospectrometric measurement was conducted at $540 \mathrm{~nm}$ for avoidance of the effect by the formation of sugar-derived osazones in plant materials. Total ascorbate contents were also determined by the ASO with Dithiothreitol (DTT) method (24). One microliter of $1 \mathrm{M}$ DTT was added to neutralized extracts $(250 \mu \mathrm{L})$, and was incubated for $5 \mathrm{~min}$ at room temperature to reduce DHA to AsA. After reduction of DHA, this sample was applied to determine total ascorbate content. DHA was determined by subtracting AsA content foredetermined from the extracts without DTT treatment.

Electrophoresis. Sodium dodecyl sulfate-polyacrylamide gel electrophoresis (SDS-PAGE) of E. coli extracts and purified DHAR was performed by the method of Laemmli (25). E. coli cells at OD $_{600} 0.6$ harboring pQEDHAR were incubated for 1 to $3 \mathrm{~h}$ after the addition of $1 \mathrm{mM}$ IPTG, and whole cells were suspended in 1/10 volume loading buffer for SDS-PAGE $(50 \mathrm{mM}$ Tris- $\mathrm{HCl}$, $\mathrm{pH} 6.8,2 \%(\mathrm{w} / \mathrm{v})$ SDS, and $100 \mathrm{mM} \beta \mathrm{ME})$ and then boiled for $5 \mathrm{~min}$. These whole cell extracts $(10 \mu \mathrm{L})$ were applied to a lane of a polyacrylamide gel. DHAR was immunodetected with rabbit polyclonal antibodies against rice DHAR by the alkaline phosphatase/X-phosphate/ bromo-4-chloro-3-indolyl phosphate method (13).

Protein. Protein content was determined by the Coomassie dye binding method (26) using a microplate reader (MTP-300; Corona Electric, Tsukuba) and a filter of around $595 \mathrm{~nm}$. Bovine serum albumin was used as 
a standard protein.

\section{RESULTS AND DISCUSSION}

Expression, purification, and characterization of rDHAR

When M15 and SG13009 were selected as host strains for the expression vector for rDHAR, doublet major bands of around $27 \mathrm{kDa}$ were accumulated on SDS-PAGE (Fig. 1A). Recombinant DHAR was also purified as doublet polypeptides at around $27 \mathrm{kDa}$ by $\mathrm{Ni}^{2+}$ NTA affinity chromatography (Fig. 1B). The theoretical molecular mass of rice DHAR, from its nucleotide sequences, is about $26 \mathrm{kDa}$ (22) (data not shown), and DHAR is not glycosylated in its native form (13). Therefore, the larger polypeptide appeared to be full-length rDHAR, and the smaller band in the IPTG-treated E. coli cells appeared to be by-products from either incomplete protein biosynthesis or prompt degradation after protein synthesis.

The ratios of expression intensity between the doublet bands around $27 \mathrm{kDa}$ were unaffected by changes in the duration of IPTG treatment (Fig. 1) and temperature to $25^{\circ} \mathrm{C}$ (data not shown). This result suggests that prompt degradation was not probable. The frequency table of codon usage in E. coli on the Codon Usage Database (www.kazusa.or.jp/codon/) indicates that rice DHAR cDNA contains a minor codon (CTA for Leu177) for E. coli, owing to the higher GC ratios in the rice genome. The predicted difference in molecular mass between the double bands of purified rDHAR on SDSPAGE (Fig. 1) was about $3 \mathrm{kDa}$, whereas the molecular mass of the C-terminal peptide region downstream of Leu 177 is about $4.0 \mathrm{kDa}$ (data not shown). This strongly suggests that the two small polypeptides in IPTG-treated E. coli cells resulted from irregular termination of protein synthesis because of scarcity of tRNA for CTA ${ }^{\text {Leu }}$.

To solve this problem, we changed the host strain for rDHAR production to BL21-RIL. BL21-RIL is a modified E. coli strain with extra copies of the E. coli $\arg U$, ileY, and leuW tRNA genes which rarely occur (AGG/AGA for Arg, AUA for Ile, and CUA for Leu, respectively) in E. coli. These codons commonly occur in rice (Oryza sativa) (data not shown). By using this strain, we expected to decrease the likelihood of irregular termination of protein synthesis as a result of scarcity of specific tRNAs. In fact, IPTG-induced expression and homogeneity of recombinant DHAR were greatly increased in these special host cells (Fig. 2A). Purified rDHAR from these host cells was homogenous on SDS-PAGE (Fig. 2B) and crossreacted with the antibody against native DHAR from rice bran (Fig. 2C). These results indicated that application of E. coli cells from strain BL21-RIL, in which the tRNAs for minor codons were supplemented, improved

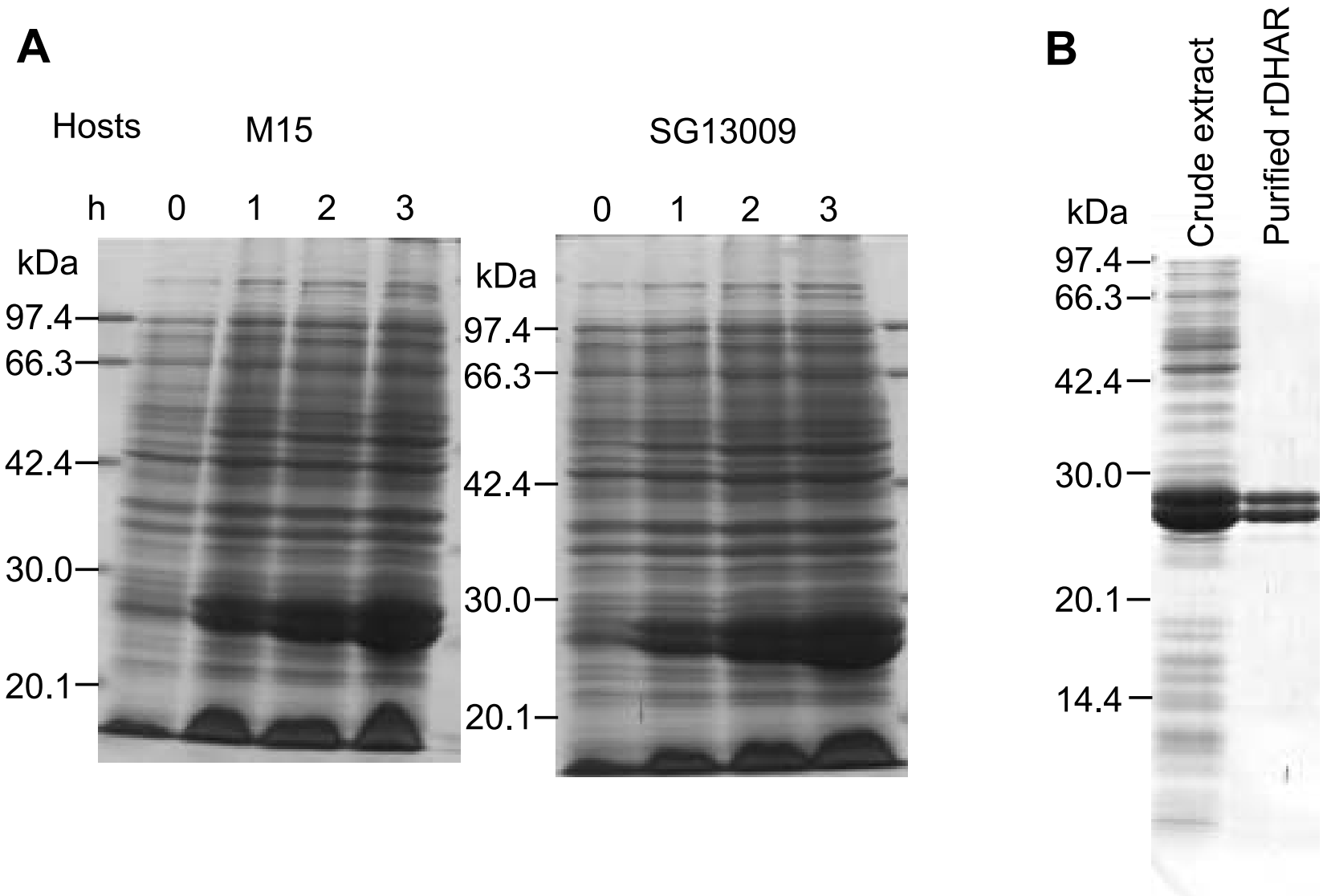

Fig. 1. Expression of multiple-length rDHAR in E. coli strains M15 and SG13009. A: Whole cell extracts collected at the indicated times after the addition of $1 \mathrm{mM} \mathrm{IPTG}$, and whole cell extracts $(10 \mu \mathrm{L})$ prepared as described in "Materials and Methods" were applied to SDS-PAGE. B: Whole cell extracts $(10 \mu \mathrm{L})$ and purified rDHAR from strain M15 cells harboring pQE-DHAR $(2 \mu \mathrm{g})$ were applied to SDS-PAGE. 
A

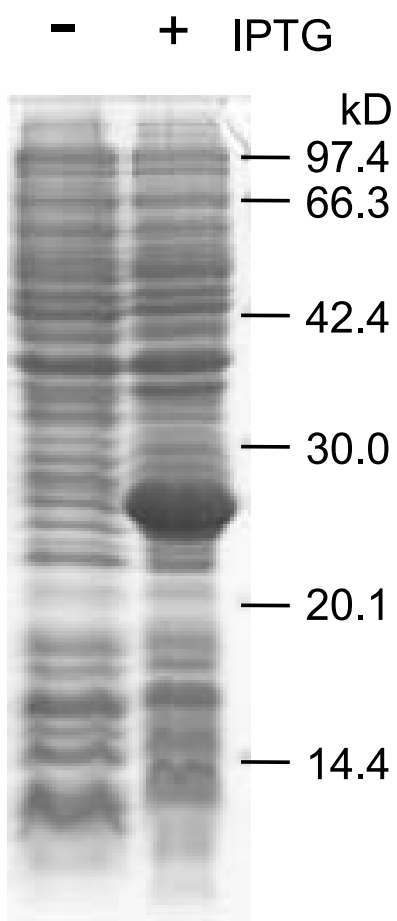

B

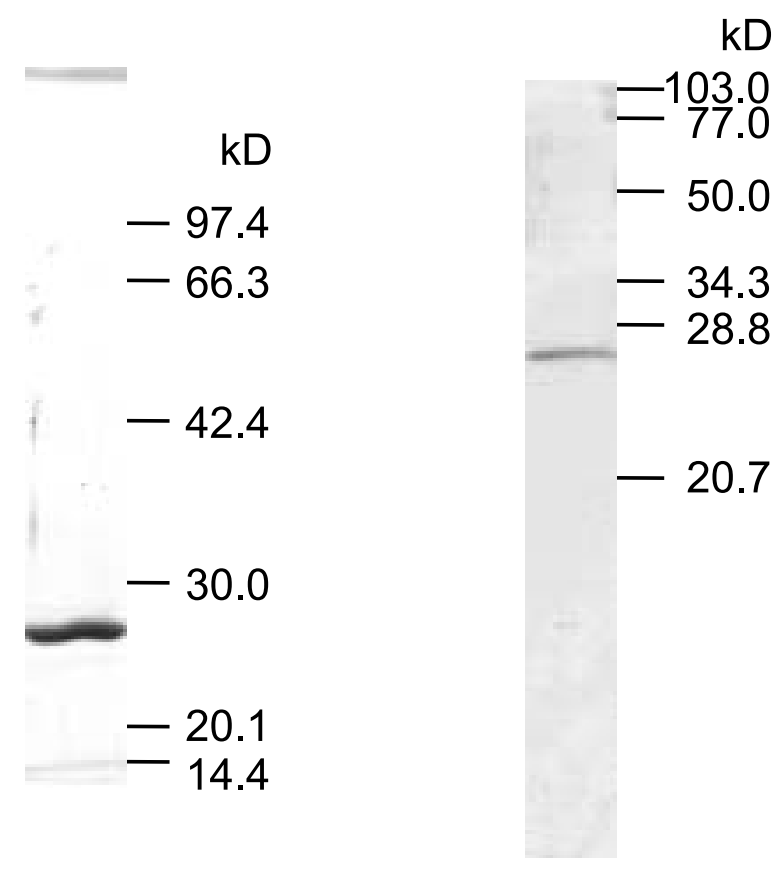

Fig. 2. Expression of a recombinant DHAR in E. coli supplemented with tRNAs for minor codons. A: Whole cell extracts from strain BL21-RIL harboring pQE-DHAR and pREP5 were prepared $3 \mathrm{~h}$ after the addition of sterilized water (-) and 1 mM IPTG (+), and each $10 \mu \mathrm{L}$ was applied to SDS-PAGE. B: Purified rDHAR $(2 \mu \mathrm{g})$ from strain BL21-RIL harboring pQEDHAR and pREP4 was applied to SDS-PAGE. C: Purified rDHAR ( $2 \mathrm{ng})$ mixed with bovine serum albumin $(2 \mu \mathrm{g})$ was subjected to Western blotting analysis. Antiserum prepared against rice DHAR (13) was used after 4,000-fold dilution.

Table 1. Molecular properties of rDHAR.

\begin{tabular}{|c|c|c|c|}
\hline Source & $\begin{array}{l}\text { Rice cytosolic } \\
\text { DHAR }^{1}\end{array}$ & $\begin{array}{l}\text { Rice recombinant DHAR } \\
\text { (E. coli) }\end{array}$ & $\begin{array}{c}\text { Spinach chloroplastic } \\
\text { DHAR }^{2}\end{array}$ \\
\hline 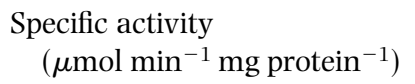 & 49.1 & 350 & 310 \\
\hline \multicolumn{4}{|l|}{$\mathrm{Km}(\mathrm{mM})$ for } \\
\hline DHA & 0.35 & 0.35 & 0.07 \\
\hline GSH & 0.84 & 1.00 & 1.1 \\
\hline Optimum pH & 8.2 & 8.2 & 7.9 \\
\hline \multicolumn{4}{|c|}{$\begin{array}{l}\text { Residual activity (\%) after treatment with } \\
\text { Iodoacetic acid }\end{array}$} \\
\hline $0.1 \mathrm{~mm}$ & 52 & 41 & - \\
\hline $1.0 \mathrm{mM}$ & 9 & 1 & 2 \\
\hline \multicolumn{4}{|l|}{ Heat } \\
\hline $80^{\circ} \mathrm{C}, 10 \mathrm{~min}$ & 90 & 1 & 18.5 \\
\hline \multicolumn{4}{|l|}{ Cyanate } \\
\hline $100 \mathrm{~mm}$ & - & 99 & - \\
\hline $500 \mathrm{~mm}$ & - & 85 & - \\
\hline
\end{tabular}

${ }^{1}$ Kato et al. (13), ${ }^{2}$ Shimaoka et al. (12).

the productivity of recombinant proteins.

Purified rDHAR had a specific activity of $350 \mu \mathrm{mol}$ $\min ^{-1} \mathrm{mg}$ protein ${ }^{-1}$, which was more than 7 times as high as that reported for rice bran (Table 1). The optimum $\mathrm{pH}, \mathrm{Km}$ values for DHA and GSH, and inhibition by thiol-modifying reagent were similar between native and recombinant DHAR from rice bran (Table 1). In contrast, rDHAR was more susceptible than native enzyme to heat. The reason is not clear, but it might be due to a slight modification in the structure of rDHAR by extension of the amino acid sequences with the polyhistidine tag. 
Use of rDHAR for DHA determination

For determining various environmental responses in biological systems, it is important that we are able to quantify AsA, DHA, and the redox state of AsA accurately. DHA itself does not act as an antioxidant, of course, but recent studies show that DHA has its own physiological functions. DHA is an inhibitor for $\mathrm{I} \kappa \mathrm{B} \alpha$ kinase $\beta$ (20). Transgenic plants overexpressing DHAR show a higher redox ratio (AsA/DHA) than do nontransgenic plants, and they lack the ability to regulate stomatal opening (27). AsA and DHA have distinct transport pathways. AsA is transported by a sodiumdependent active transporter (28), whereas DHA is transported by facilitated glucose transporters $(29,30)$.

There are many methods of quantifying AsA and DHA. A variety of spectrophotometric, colorimetric, fluorometric, chromatographic (high-performance liquid chromatography and gas chromatography), and electrochemical protocols for the detection of AsA and DHA have been reviewed $(31,32)$. Most protocols are based on the physicochemical properties of AsA (the reduced form). DHA can be reduced by dithiothreitol and is determined by the subtraction of AsA content from total ascorbate (AsA plus DHA) content. These protocols are potentially disadvantageous for determining DHA concentrations precisely, because AsA is predominant in most biological samples. The classical hydrazone formation method (23) has been adopted as a primary method to determine AsA contents in biological samples and can directly determine DHA concentrations, but it is relatively complicated and time-consuming.

The enzymatic method is generally simple and rapid in terms of various quantitative protocols, and ascorbate oxidase has been used in the determination of AsA and DHA concentrations. However, reduction of DHA by DTT after neutralization as well as the subtraction process is indispensable when we determine DHA content. We expected that we could directly determine DHA by using DHAR obtained here.

To establish the protocol, we took precautions against a potential problem to keep DHA stable, i.e., autooxidation of AsA. Autooxidation of AsA proceeds rapidly under alkaline conditions and is accelerated in the presence of transient metal ions such as $\mathrm{Fe}$ and $\mathrm{Cu}$ (33). Optimum $\mathrm{pH}$ is about 8.0 for rDHAR (Table 1) and about 5.6 for ascorbate oxidase (data not shown). We set the $\mathrm{pH}$ for the determination of DHA at 6.0 to suppress autooxidation of AsA. The activity of rDHAR at pH 6.0 was only about $20 \%$ of that at $\mathrm{pH} 8.0$ (data not shown), but the high specific activity of rDHAR (Table 1) enabled the assay to occur at weakly acidic $\mathrm{pH}$. Moreover, the addition of a metal ion chelator EDTA ( 1 $\mathrm{mM}$ ) coupled with $\mathrm{pH}$ condition enabled the complete inhibition of autooxidation of AsA (data not shown). There is one previous report of the determination of DHA enzymatically, but it contains an empirical, not theoretical, parameter in the equation for the determination of DHA, probably because of the low specific activity of DHAR and the high concentration of glu-

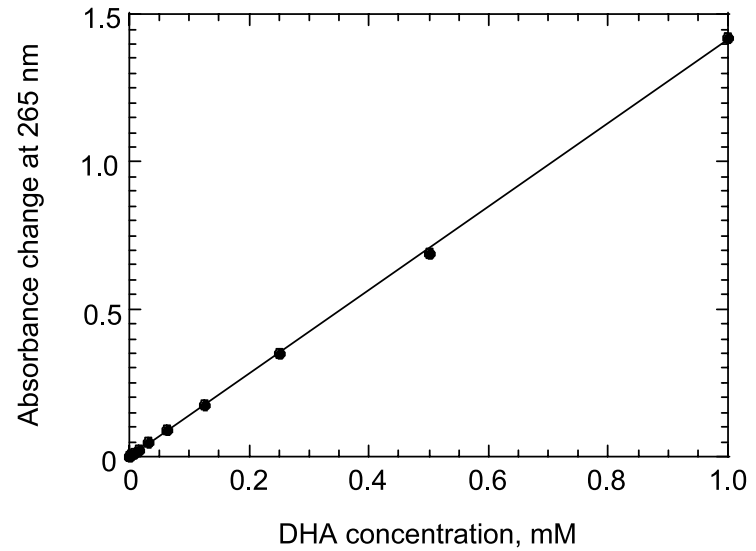

Fig. 3. Calibration of DHA detection with rDHAR. The indicated concentrations of DHA in 5\% metaphosphoric acid $(100 \mu \mathrm{L})$ was applied to the reaction mixture $(1 \mathrm{~mL})$ as described in "Materials and Methods." The absorbance changes at $265 \mathrm{~nm}$ by the addition of the reduced form of glutathione were determined, the absorbance change in the absence of DHA (usually $\left.\Delta A_{265}=0.007\right)$ was subtracted, and the resulting data were plotted against DHA concentrations with a straight line drawn through the origin. Average values from three replicate measurements are presented with error bars as standard deviations.

tathione in the reaction mixture (21). Arrangement of the order of chemical addition and high specific activity of rDHAR can exclude this parameter in our assay system.

A calibration curve obtained by our assay system described in "Materials and Methods" exhibited good linearity $\left(R^{2}=0.9998\right)$ between 0 and $0.1 \mathrm{~mm}$ DHA in the reaction mixture (Fig. 3). In this method, we could detect at least $2 \mu \mathrm{M}$ DHA in 5\% metaphosphoric acid, although the detection limit of DHA may be increased by proteins, nucleic acids, and low molecular weight compounds including AsA in biological samples because they show absorbance at an ultraviolet wavelength around $265 \mathrm{~nm}$.

We compared our ASO and DHAR method to other existing protocols (Hydrazone formation (23) and ASO with DTT (24) method) for determination of AsA and DHA by application to a few fruit juices and vegetables (Table 2). In the ASO and DHAR method, both metaphosphoric acid and trichloroacetic acid gave the same results when they were used as the extraction solutes against fruit juices (data not shown). In vegetables, AsA, DHA and total ascorbate content determined by our method were in good agreement with those determined by the Hydrazone formation method, which indicates that the ASO and DHAR method works well. In contrast, DHA contents tended to be higher in the hydrozone formation method and lower in the ASO with DTT method than the ASO and DHAR method in fruit juices. In the hydrazone formation method, DHA seemed to be overestimated by osazones derived from other sugars contained in fruit juices. ASO and DHAR does not work sugar other than AsA and DHA respec- 
Table 2. AsA, DHA and total ascorbate contents in fruit juices and vegetables measured by ASO and DHAR, Hydrazone formation (23) and ASO with DTT (24) methods.

\begin{tabular}{|c|c|c|c|c|}
\hline & & ASO and DHAR & Hydrazone formation & ASO with DTT \\
\hline \multirow[t]{3}{*}{ Orange juice } & AsA & $1.76 \pm 0.04$ & $1.66 \pm 0.04^{*}$ & \\
\hline & DHA & $0.23 \pm 0.01$ & $0.31 \pm 0.03^{* *}$ & $0.08 \pm 0.09^{*}$ \\
\hline & Total & $1.99 \pm 0.04$ & $1.97 \pm 0.02$ & $1.84 \pm 0.08^{*}$ \\
\hline \multirow[t]{3}{*}{ Grapefruit juice } & AsA & $1.57 \pm 0.02$ & $1.52 \pm 0.03^{*}$ & \\
\hline & DHA & $0.05 \pm 0.01$ & $0.14 \pm 0.02^{* *}$ & $0.01 \pm 0.04$ \\
\hline & Total & $1.62 \pm 0.02$ & $1.66 \pm 0.02$ & $1.58 \pm 0.04$ \\
\hline \multirow[t]{3}{*}{ Spinach } & AsA & $6.09 \pm 0.01$ & $6.17 \pm 0.05$ & \\
\hline & DHA & $0.21 \pm 0.03$ & $0.20 \pm 0.02$ & - \\
\hline & Total & $6.31 \pm 0.03$ & $6.26 \pm 0.05$ & - \\
\hline \multirow[t]{3}{*}{ Onion } & AsA & $0.22 \pm 0.00$ & $0.24 \pm 0.04$ & \\
\hline & DHA & $0.00 \pm 0.00$ & $0.03 \pm 0.03$ & - \\
\hline & Total & $0.22 \pm 0.01$ & $0.27 \pm 0.02^{*}$ & - \\
\hline
\end{tabular}

Average values from three replicate measurements are presented with standard deviations. ${ }^{*} p<0.1 ;{ }^{* *} p<0.01$ versus the ASO and DHAR method by Student's $t$-test.

tively, so the presented data show the robustness of this enzymatic method. In the ASO with DTT method, the reduction of DHA with DTT and its stability is sometimes insufficient during the course of assay protocol, which resulted in large standard deviations in total ascorbate contents. AsA contents determined by the hydrazone formation method and DHA contents determined by the ASO with DTT method showed relatively higher standard deviations, which is essential to the principle that they are obtained as the subtraction of either DHA or AsA contents from total ascorbate contents, respectively.

Finally, the protocol is also advantageous in simplicity because no pretreatment of samples is needed other than extraction, and measurements are accomplished in only $5 \mathrm{~min}$. As a whole, the protocol presented here can be regarded as an equivalent or a superior method to other conventional methods in sensitivity and accuracy. This protocol will give us more reliable data in biological samples.

\section{Acknowledgments}

This work was partly supported as a High-Tech Research Center Project for Private Universities, with a matching fund subsidy from MEXT (Ministry of Education, Culture, Sports, Science and Technology of Japan) for 2000-2005.

\section{REFERENCES}

1) Asada K, Takahashi M. 1987. Production and scavenging of active oxygen in photosynthesis. In: Photoinhibition (Kyle DJ, Osmond CB, Armtzen CJ, eds), p 227-287. Elsevier, Amsterdam.

2) Nishikimi M, Fukuyama R, Minoshima S, Shimizu N, Yagi K. 1994. Cloning and chromosomal mapping of the human nonfunctional gene for L-gulono- $\gamma$-lactone oxidase, the enzyme for L-ascorbic acid biosynthesis missing in man. J Biol Chem 269: 13685-13688.

3) Smirnoff N. 2000. Ascorbate biosynthesis and function in photoprotection. Phil Trans R Soc Lond B 355: 14551464.

4) Asada K. 1999. The water-water cycle in chloroplasts: Scavenging of active oxygens. Ann Rev Plant Physiol Plant Mol Biol 50: 601-639.

5) Wheeler GL, Jones MA, Smirnoff N. 1998. The biosynthetic pathway of vitamin $\mathrm{C}$ in higher plants. Nature 393: 365-369.

6) Valpuesta V, Botella MA. 2004. Biosynthesis of L-ascorbic acid in plants: new pathways for an old antioxidant. Trends Plant Sci 9: 573-577.

7) Amako K, Chen G-X, Asada K. 1994. Separate assays specific for ascorbate peroxidase and guaiacol peroxidase and for the chloroplastic and cytosolic isozymes of ascorbate peroxidase in plants. Plant Cell Physiol 34: 497-504.

8) Miyake C, Asada K. 1994. Ferredoxin-dependent photoreduction of the monodehydroascorbate radical in spinach thylakoids. Plant Cell Physiol 33: 541-553.

9) Hossain MA, Asada K. 1985. Monodehydroascorbate reductase from cucumber is a flavin adeninedinucleotide enzyme. J Biol Chem 260: 12920-12926.

10) Sano S, Asada K. 1994. cDNA cloning of monodehydroascorbate radical reductase from cucumber: a high degree of homology in terms of amino acid sequence between this enzyme and bacterial flavoenzymes. Plant Cell Physiol 35: 425-437.

11) Hossain MA, Asada K. 1984. Purification of dehydroascorbate reductase from spinach and its characterization as a thiol enzyme. Plant Cell Physiol 25: 85-92.

12) Shimaoka T, Yokota A, Miyake C. 2000. Purification and characterization of chloroplast dehydrogenase reductase from spinach leaves. Plant Cell Physiol 41: 1110-1118.

13) Kato Y, Urano J, Maki Y, Ushimaru T. 1997. Purification and characterization of dehydroascorbate reductase from rice. Plant Cell Physiol 38: 173-178. 
14) Chen Z, Young TE, Ling J, Chang SC, Gallie DR. 2003. Increasing vitamin $\mathrm{C}$ content of plants through enhanced ascorbate recycling. Proc Natl Acad Sci USA 100: 3525-3530.

15) Kwon SY, Choi SM, Ahn YO, Lee HS, Lee HB, Park YM, Kwak SS. 2003. Enhanced stress-tolerance of transgenic tobacco plants expressing a human dehydroascorbate reductase gene. J Plant Physiol 160: 347-353.

16) Ushimaru T, Nakagawa T, Fujioka Y, Daicho K, Naito M, Yamauchi Y, Nonaka H, Amako K, Yamawaki K, Murata N. 2006. Transgenic Arabidopsis plants expressing the rice dehydroascorbate reductase gene are resistant to salt stress. J Plant Physiol in press.

17) Potters G, Horemans N, Caubergs J, Asard H. 2000. Ascorbate and dehydroascorbate influence cell cycle progression in a tobacco cell suspension. Plant Physiol 124: 17-20.

18) Kato N, Esaka M. 2000. Expansion of transgenic tobacco protoplasts expressing pumpkin ascorbate oxidase is more rapid than that of wild-type protoplasts. Planta 210: 1018-1022.

19) Paciolla C, De Tullio MC, Chiappetta A, Innocenti AM, Bitonti MB, Liso R, Arrigoni O. 2001. Short- and longterm effects of dehydroascorbate in Lupinus albus and Allium cepa. Plant Cell Physiol 42: 857-863.

20) Cárcamo JM, Pedraza A, Borquez-Ojeda O, Zhang B, Sanchez R, Golde DW. 2004. Vitamin C is a kinase inhibitor: dehydroascorbic acid inhibits $\mathrm{I} \kappa \mathrm{B} \alpha$ kinase $\beta$. Mol Cell Biol 24: 6645-6652.

21) Every D. 1996. Enzymatic method to determine dehydroascorbic acid in biological samples and in bread dough at various stages of mixing. Anal Biochem 242: 234-239.

22) Urano J, Nakagawa T, Maki Y, Masumura T, Tanaka K, Murata N, Ushimaru T. 2000. Molecular cloning and characterization of a rice dehydroascorbate reductase. FEBS Lett 466: 107-111.
23) Okamura M. 1979. Uptake of L-ascorbic acid and Ldehydroascorbic acid by human erythrocytes and HeLa cells. J Nutr Sci Vitaminol 25: 269-279.

24) Rao MV, Ormrod DP. 1995. Ozone exposure decreases UVB sensitivity in a UVB-sensitive flavonoid mutant of Arabidopsis. Photochem Photobiol 61: 71-78.

25) Laemmli UK. 1970. Cleavage of structural proteins during the assembly of the head of bacteriophage T4. Nature 227: 680-685.

26) Bradford MM. 1976. A rapid and sensitive method for the quantitation of microgram quantities of protein utilizing the principle of protein-dye binding. Anal Biochem 72: $248-254$.

27) Chen Z, Gallie DR. 2004. The ascorbic acid redox state controls guard cell signaling and stomatal movement. Plant Cell 16: 1143-1162.

28) Tsukaguchi H, Tokui T, Mackenzie B, Berger UV, Chen XZ, Wang Y, Brubaker RF, Hediger MA. 1999. A family of mammalian $\mathrm{Na}^{+}$-dependent L-ascorbic acid transporters. Nature 399: 70-75.

29) May JM, Qu ZC, Whitesell RR. 1995. Ascorbic acid recycling enhances the antioxidant reserve of human erythrocytes. Biochemistry 34: 12721-12728.

30) Vera JC, Rivas CI, Velasquez FV, Zhang RH, Concha II, Golde DW. 1995. Resolution of the facilitated transport of dehydroascorbic acid from its intracellular accumulation as ascorbic acid. J Biol Chem 270: 23706-23712.

31) Washko PW, Welch RW, Dhariwal KR, Wang Y, Levine M. 1992. Ascorbic acid and dehydroascorbic acid analyses in biological samples. Anal Biochem 204: 1-14.

32) Moeslinger T, Brunner M, Spieckermann PG. 1994. Spectrophotometric determination of dehydroascorbic acid in biological samples. Anal Biochem 221: 290-296.

33) Bielski BHJ. 1982. Chemistry in ascorbic acid radicals. In: Ascorbic Acid: Chemistry, Metabolism and Uses (Seib PA, Tolbert BM, eds), p 81-100. American Chemical Society, Washington DC. 